\title{
ANALISIS KEPUASAN KONSUMEN TERHADAP PRODUK COKELAT MONGGO DI KOTAGEDE, DAERAH ISTIMEWAYOGYAKARTA
}

\author{
RAj. Tysa Kusumowardhani ${ }^{(1)}$, Mohamad Harisudin ${ }^{(2)}$, Susi Wuri Ani ${ }^{(3)}$ \\ Program Studi Agribisnis Fakultas Pertanian, Universitas Sebelas Maret Surakarta \\ JI. Ir. Sutami No. 36A Kentingan Surakarta 57126 Telp/Fax (0271) 637457 \\ Email: rajtysa@gmail.com
}

\begin{abstract}
Abstrak
Penelitian ini bertujuan untuk mengetahui kepuasan konsumen Cokelat Monggo serta rekomendasi strategi yang tepat untuk meningkatkan kepuasan konsumen produk Cokelat Monggo. Metode penelitian yang digunakan adalah deskriptif analitis. Pengambilan lokasi penelitian secara sengaja. Metode analisis data yang digunakan adalah metode deskripstif, metode Customer Satisfaction Index (CSI) dan Importance Performance Analysis (IPA). Berdasarkan hasil perhitungan Costumer Satisfaction Index (CSI), tingkat kepuasan konsumen produk Cokelat Monggo yaitu sebesar $76.93 \%$ yang menunjukkan bahwa secara keseluruhan konsumen sudah merasa puas.Alternatif strategi pemasaran yang direkomendasikan yaitu pada strategi produk, pencantuman informasi kandungan gizi disetiap varian produk Cokelat Monggo. Alternatif strategi distribusi yang dapat dilakukan adalah menyediakan prasarana penjualan atau display. Alternatif strategi harga yang disarankan adalah membuat promosi harga produk Cokelat Monggo. Alternatif strategi promosi yang dapat dilakukan menjadi sponsor kegiatan tertentu dan metode Word of Mouth (WOM). Peningkatan layanan informasi dapat dilakukan dengan membuat menu khusus untuk kritik dan saran, memperjelas akun resmi Cokelat Monggo disetiap produk maupun iklan dan promosi serta memperbaharui data website.
\end{abstract}

Kata kunci : Customer Satisfaction Index, Importance Performance Analysis, Kepuasan Konsumen

\begin{abstract}
This study aims to find out the customer satisfaction of Monggo Chocolate and the right strategy recommendations to improve consumer satisfaction of Monggo Chocolate products. The research used descriptive method. Intentional research location retrieval. Data analysis method used is descriptive method, Customer Satisfaction Index (CSI) method and Importance Performance Analysis (IPA). Based on the results of the Customer Satisfaction Index (CSI), the level of consumer satisfaction of Chocolate Monggo products is $76.93 \%$ which indicates that overall consumers are satisfied. Recommended alternative marketing strategies are the product strategy, the inclusion of information on the nutritional content of each Monggo Chocolate product variant. The alternative distribution strategy that can be done is to provide sales or display infrastructure. The recommended alternative pricing strategy is to make a price promotion for Monggo Chocolate products. Alternative promotional strategies that can be carried out to sponsor certain activities and the Word of Mouth (WOM) method. Information service improvement can be done by creating a special menu for criticism and suggestions, clarifying the official Monggo Chocolate account in each product and advertising and promotion as well as updating website data.
\end{abstract}

Keywords : Customer Satisfaction Index, Importance Performance Analysis, Consumer Satisfaction 


\section{PENDAHULUAN}

Agroindustri merupakan bagian agribisnis yang memproses dan mentransformasikan hasil pertanian untuk menghasilkan suatu produk setengah jadi atau produk jadi. Potensi perkembangan agroindustri di Indonesia akan semakin pesat karena posisi pertanian yang merupakan sektor andalan dalam pembangunan nasional (Udayana, 2011).Ada beberapa sektor agroindustri yang menjadi perhatian utama pemerintah karena diharapkan bisa menjadi industri andalan masa depan.Kakao merupakan salah satu komoditas perkebunan yang merupakan komoditas unggulan nasional dan memberikan sumbangan devisa ketiga terbesar setelah kelapa sawit dan karet (Hasibuanet al, 2012).

Buah kakao yang sudah dipanen akan diambil bijinya untuk melalui proses pengolahan. Ada beberapa produk hasil olahan biji kakao akan tetapi yang paling dikenal adalah cokelat. Berdasarkan Outlook Komoditi Kakao (2016) konsumsi cokelat di Indonesia dibedakan menjadi konsumsi cokelat instan dan cokelat bubuk. Konsumsi cokelat instan di Indonesia selama periode tersebut meningkat sebesar $22,16 \%$ per tahun, sedangkan konsumsi cokelat bubuk meningkat $53,77 \%$ per tahun. Hal tersebut membuktikan bahwa cokelat semakin diminati oleh konsumen di Indonesia walaupun masih rendah dibandingkan dengan negara-negara Eropa yang notabene bukan negara penghasil cokelat terbesar (Kemenperin, 2017).

Seiring dengan peningkatan konsumsi cokelat di Indonesia menjadikan industri cokelat berkembang pesat.Salah satu daerah yang memiliki perkembangan industri cokelat yang pesat adalah Daerah Istimewa Yogyakarta. Daerah Istimewa Yogyakarta sendiri merupakan sebuah daerah di Indonesia yang terkenal sebagai daerah tujuan wisata, bahkan merupakan daerah tujuan wisata utama khususnya di Pulau Jawa.Salah satu industri produk cokelat di Daerah Istimewa Yogyakarta yang sangat terkenaladalah
Cokelat Monggo.Mengusung produk cokelat yang berkualitas, Cokelat Monggo hadir dan terus berkembang selama 13 tahun terakhir untuk memenuhi keinginan konsumen terhadap cokelat berkualitas asli Indonesia. Sebagai salah satu industri cokelat di Daerah Istimewa Yogyakarta, hal yang menjadi perhatian utama dari Cokelat Monggo adalah kepuasan konsumen.Menurut Kirom (2009), pengukuran kepuasan konsumen perlu dilakukan dengan alasan yaitu pertama, tingkat pesaing yang semakin meningkat. Kedua, semakin besar investasi yang dicurahkan oleh perusahaan untuk mengimplementasikan program kepuasan konsumen. Ketiga, harapan konsumen yang berubah dari waktu ke waktu.Oleh karena itu Cokelat Monggo perlu melakukan analisis kepuasan konsumen sehingga mengetahui kepuasan konsumennya terhadap produk mereka dan sebagai masukan untuk perkembangan produk Cokelat Monggo kedepannya.

\section{METODE PENELITIAN}

\section{Metode Dasar Penelitian}

Metode dasar penelitian yang digunakan adalah deskriptif, Teknik penelitian yang digunakan adalah teknik survey.

\section{Metode Penentuan Lokasi}

Penelitian ini dilaksanakan di outlet Cokelat Monggo yang berlokasi di Kotagede. Penentuan lokasi tersebut sebagai tempat penelitian dilakukan secara sengaja (purposive) dengan alasan Cokelat Monggo merupakan pioner oleh - oleh khas Daerah Istimewa Yogyakarta yang berupa cokelat dan memiliki distribusi produk yang luas. Alasan lainnya adalah karena outlet Cokelat Monggodi Kotagede merupakan outlet pertama yang dimiliki Cokelat Monggo dan terletak di kawasan yang memiliki persaingan dengan produk cokelat sejenis. Selain itu unsur keterjangkauan lokasi penelitian oleh peneliti, baik dilihat dari segi tenaga, dana maupun waktu. 
Kusumowardhani, dkk. 2019

\section{Metode Penentuan Sampel}

Penentuan sampel penelitian dengan metode purposive sampling. Sampel yang diambil sebesar 100 responden.

\section{Uji Instrumen Penelitian}

Untuk mendapatkan sebuah instrumen penelitian yang memenuhi standar, minimal ada dua syarat yang harus dipenuhi yaitu Uji Validitas dan Uji Reliabilitas (Sukardi et al, 2010). Uji validitas dan uji reliabilitas dilakukan terhadap 30 jawaban responden awal yang mengisi kuesioner. Pengujian validitas setiap butir pertanyaan di dalam kuesioner dilakukan dengan menggunakan alat ukur pearson corelation dengan bantuan perangkat lunak SPSS 17.0 for Windows. Pengujian reliabilitas dilakukan dengan menggunakan rumus AlphaCronbach dengan alat bantu perangkat lunak SPSS 17.0 for Windows.

\section{Metode Analisis Data}

Analisis Deskriptif

Analisis deskriptif digunakan dalam menggambarkan karakteristik dan keputusan pembelian konsumen Cokelat Monggo dengan cara mentabulasikan secara sederhana data yang diperoleh.

Customer Satisfaction Index (CSI)

Metode ini digunakan untuk menentukan tingkat kepuasan pelanggan secara menyeluruh dengan pendekatan yang mempertimbangkan tingkat kepentingan dari variabel-variabel yang diukur. Tingkat kepuasan responden secara menyeluruh dapat dilihat dari kriteria tingkat kepuasan pelanggan. Kepuasan tertinggi akan dicapai apabila Customer Satisfaction Index (CSI) menunjukkan rentang 100 persen. Rentang kepuasan konsumen berkisar antara 1-100 persen. Untuk membuat skala linear numerik, maka hal pertama yang dilakukan adalah mencari rentang skala (RS) dengan rumus:

$$
R S=\frac{m-n}{b}
$$

Berdasarkan rumus tersebut maka diperoleh skala kepuasan responden sebagai berikut : $0 \%<\mathrm{CSI}<20 \%=$ sangat tidak puas $20 \%<\mathrm{CSI}<40 \%=$ tidak puas
$40 \%<\mathrm{CSI}<60 \%=$ cukup puas

$60 \%<\mathrm{CSI}<80 \%=$ puas

$80 \%<\mathrm{CSI}<100 \%$ = sangat puas

Importance Performance Analysis (IPA)

Pada penelitian ini tingkat kepuasan konsumen dapat diukur melalui tingkat kepentingan yang dapat mewakili harapan dari konsumen dan tingkat kinerja dari atribut produk yang dinilai. Tingkat kepentingan dan kinerja dapat dinilai dengan menggunakan nilai skor skala lima tingkat (Likert).Penilaian tingkat kinerja dapat mempengaruhi kepuasan konsumen yang akan diwakili oleh huruf $\mathrm{X}$, sedangkan untuk tingkat kepentingan diwakili oleh huruf Y.Masing-masing atribut diposisikan dalam diagram tersebut berdasarkan skor ratarata, dimana skor rata-rata penilaian kinerja $(X)$ menunjukkan posisi suatu atribut pada sumbu $X$, sedangkan posisi atribut pada sumbu $Y$ ditunjukkan oleh skor rata-rata tingkat kepentingan (Y).Menurut (Martilla dan James, 1977) hubungan antara tingkat kinerja $X$ dan kepentingan $\mathrm{Y}$ yang diperoleh dari responden dapat dijabarkan dalam diagram kartesius,masing-masing kuadran pada gambar ini menunjukan keadaan yang berbeda:

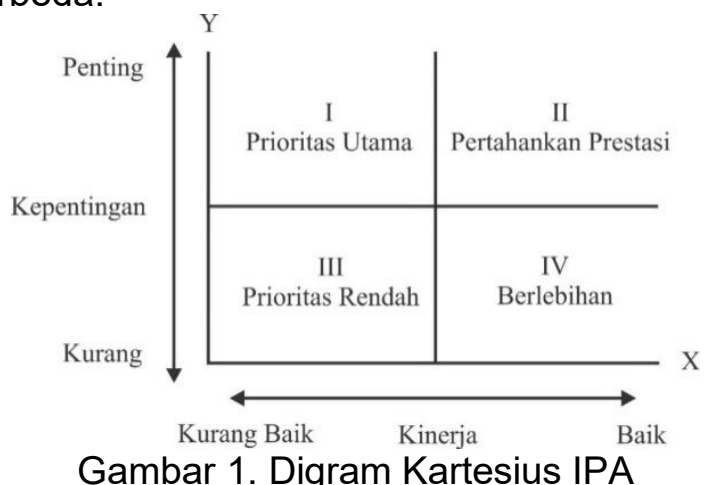

\section{HASIL DAN PEMBAHASAN}

\section{Uji Instrumen}

Uji validitas dan reliabilitas pra survei tingkat kinerja dan tingkat kepentingan dalam penelitian ini menggunakan 30 responden. Hasil dari uji validitas menunjukan bahwa tidak terdapat atribut yang memiliki nilai Pearson Correlation dibawah atau lebih kecil dari 0.361. Hasil uji reliabilitas dengan cronbach's alpha ini 
Kusumowardhani, dkk. 2019

menunjukan bahwa semua atribut Cokelat Monggo dinyatakan sangat reliabel karena memiliki nilai alpha 0.859 untuk tingkat kinerja dan 0.987 untuk tingkat kepentingan berada pada rentang alpha $0.80-1.00$.

\section{Karakteristik Responden}

Konsumen yang menjadi responden dalam penelitian ini adalah konsumen yang berada di lokasi penelitian saat dilaksanakannya survei dan bersedia untuk mengisi kuisioner. Jumlah konsumen yang dijadikan responden berjumlah 100 orang. Berdasarkan hasil penelitian karakteristik konsumen Cokelat Monggo, yaitu berada pada sebaran usia pada konsumen berumur 17-24 tahun, dengan jenis kelamin perempuan dan pekerjaan mayoritas konsumen adalah pelajar dan mahasiswa yang memiliki pendidikan rata-rata lulusan sarjana (S1) yang memiliki pendapatan rata-rata atau uang saku bagi mahasiswa dan pelajar sebesar Rp500.000- Rp1.500 000.

Karakteristik keputusan pembelian konsumen Cokelat Monggo yaitu, pada proses pengambilan keputusan pembelian konsumen biasanya membeli produk Cokelat Monggo di outlet resmi milik Cokelat Monggo, pembeli melakukan pembelian dilokasi tersebut dikarenakan ketersediaan produk serta terjamin keasliannya. Konsumen Cokelat Monggo biasanya mengetahui tentang adanya produk Cokelat Monggo melalui teman dan keluarganya. Alasan konsumen Cokelat Monggo membeli/mengkonsumsi produk Cokelat Monggo karena kualitas produk Cokelat Monggo yang dianggap bagus.

\section{Analisis Tingkat Kepuasan Konsumen}

Metode yang digunakan dalam mengukur kepuasan konsumen adalah Customer Satisfaction Index(CSI). Tanpa adanya CSI tidak mungkin manajer dapat menentukan tujuan dalam peningkatan kepuasan konsumen (Sukardi et al, 2010).

Nilai CSI produk Cokelat Monggo sebesar $76.93 \%$ yang berada pada rentang skala $60 \%$ $<\mathrm{CSI}<80 \%$ yang masuk ke dalam kategori puas. Hal ini mengindikasikan bahwa secara umum konsumen yang membeli/ mengkonsumsi Cokelat Monggo merasa puas dengan kinerja yang diberikan Cokelat Monggo. Namun masih terdapat $23.07 \%$ konsumen yang merasa belum puas dengan produk Cokelat Monggo. Menurut Sukardi et al (2010) meskipun berada pada rentang kriteria puas, akan masih ada konsumen yang belum terpuaskan maka dari itu perusahaan harus terus meningkatkan kinerjanya agar CSI meningkat sampai angka $100 \%$. Oleh karena itu, pihak Cokelat Monggo perlu meningkatkan kepuasan konsumen dengan menelusuri kepuasan konsumen terhadap atribut-atribut Cokelat Monggo agar sesuai dengan harapan yang mereka inginkan dengan cara memperbaiki kinerja, sehingga nilai CSI dapat mencapai $100 \%$ yang mengindikasikan konsumen sangat puas. Atribut yang masih perlu diperbaiki dapat dilihat dari analisis Index Perfomance Analysis (IPA).

\section{Prioritas Perbaikan Atribut}

Hasil penilaian responden berdasarkan tingkat kepentingan dan tingkat kinerja masingmasing atribut Cokelat Monggo diolah menggunakan metode Importance Performance Analysis (IPA).Berdasarkan hasil analisis dengan metode IPA yang bisa dilihat pada Gambar 2.

\section{Kuadran I}

Kuadran I menunjukan atribut yang dianggap penting oleh konsumen namun pihak Cokelat Monggo belum melakukan sesuai dengan keinginan konsumen sehingga konsumen merasa tidak puas. Atribut yang ada dalam kuadran ini perlu perhatian khusus dengan memprioritaskan dan meningkatkan kinerja. Atribut yang termasuk kedalam kuadran ini adalah iklan \& promosi dan kemudahan mendapatkan produk.

Iklan dan promosi sebagai saran untuk memperoleh informasi tentang produk Cokelat Monggo. Atribut ini merupakan suatu bentuk sosialisasi dari perusahaan mengenai produk yang dihasilkan. Atribut iklan dan promosi dirasa kurang, dikarenakan kurang gencarnya iklan dan promosi yang dilakukan oleh Cokelat Monggo terutama di daerah luar Daerah Istimewa Yogyakarta. Adanya iklan dan promosi yang merata dan menyeluruh di luar 
Kusumowardhani, dkk. 2019

Daerah Istimewa Yogyakarta diharapkan masyarakat dapat lebih mengenal produkproduk Cokelat Monggo.

Atribut kemudahan mendapatkan produk dinilai penting karena menunjukan seberapa baik distribusi produk dan usaha Cokelat Monggo agar produknya dapat dikonsumsi konsumennya. Atribut ini dinilai memiliki kinerja yang kurang baik dikarenakan produk Cokelat Monggo kurang terdistribusi secara menyeluruh ke setiap daerah yang ada di Indonesia. Walaupun Cokelat Monggo sudah merambah pasar minimarket dan supermarket akan tetapi tidak semua daerah terdistribusi.

Tabel 1. Perhitungan Customer Satisfaction Index (CSI)

\begin{tabular}{|c|c|c|c|c|c|}
\hline \multirow[b]{2}{*}{ No. } & \multirow[b]{2}{*}{ Atribut yang digunakan } & \multicolumn{2}{|c|}{ Kepentingan } & \multicolumn{2}{|c|}{ Kinerja } \\
\hline & & $\begin{array}{c}\text { Mean } \\
\text { Importance } \\
\text { Score }\end{array}$ & $\begin{array}{l}\text { Weight } \\
\text { Factors }\end{array}$ & $\begin{array}{l}\text { Uean Performance } \\
\text { Score }\end{array}$ & Weight Score \\
\hline 1. & Iklan dan Promosi & 4.26 & 0.063 & 3.06 & 0.193 \\
\hline 2. & Merek & 4.12 & 0.061 & 3.67 & 0.224 \\
\hline 3. & Banyak dikonsumsi orang & 3.88 & 0.057 & 3.33 & 0.191 \\
\hline 4. & Prestige / kebanggaan & 3.17 & 0.047 & 3.51 & 0.165 \\
\hline 5. & Kemudahan Mendapatkan Produk & 4.37 & 0.064 & 3.52 & 0.228 \\
\hline 6. & Kemasan & 4.38 & 0.065 & 4.22 & 0.274 \\
\hline 7. & Variasi Rasa & 4.46 & 0.066 & 4.29 & 0.284 \\
\hline 8. & Informasi tanggal kadaluarsa & 4.59 & 0.068 & 4.12 & 0.280 \\
\hline 9. & Informasi Kandungan Gizi & 4.38 & 0.065 & 3.84 & 0.249 \\
\hline 10. & Jaminan Halal & 4.55 & 0.067 & 4.17 & 0.281 \\
\hline 11. & Layanan Informasi & 4.03 & 0.059 & 3.77 & 0.225 \\
\hline 12. & Aroma & 4.03 & 0.059 & 3.83 & 0.229 \\
\hline 13. & Kepadatan & 4.14 & 0.061 & 3.82 & 0.234 \\
\hline 14. & Tekstur & 4.22 & 0.062 & 4.1 & 0.256 \\
\hline 15. & Aftertaste & 4.27 & 0.063 & 4.12 & 0.261 \\
\hline 16. & Kesesuaian Harga dengan Kualitas & 4.5 & 0.066 & 3.96 & 0.264 \\
\hline & $\begin{array}{l}\text { Weight Score Total } \\
\text { Customer Satisfaction Index (\%) }\end{array}$ & & & & $\begin{array}{l}3.846 \\
76.93\end{array}$ \\
\hline
\end{tabular}

Sumber : Analisis Data Primer, 2018

\section{Kuadran II}

Atribut dalam kuadran ini merupakan atribut yang dianggap penting oleh pelanggan dan atribut-atribut tersebut dinilai memiliki tingkat kepuasan yang tinggi pula bagi pelanggan dan sudah sesuai dengan apa yang dirasakan oleh konsumen sehingga konsumen merasakan kepuasan (nilai rata-rata kepentingan dan kinerja berada di atas nilai rata-rata total kepentingan dan kinerja). Atribut yang termasuk kedalam kuadaran II adalah kemasan, variasi rasa, informasi tanggal kadaluarsa, informasi kandungan gizi, jaminan halal, tekstur, aftertaste dan kesesuaian harga dengan kualitas.

Kuadran III

Atribut-atribut yang berada pada Kuadran ini memiliki nilai rata-rata kepentingan yang nilainya lebih kecil dari nilai rata-rata totalnya dan juga memiliki nilai rata-rata kinerja yang lebih kecil dari nilai rata-rata totalnya. Kuadran III (prioritas rendah) merupakan wilayah yang memuat atribut dianggap kurang penting bagi konsumen dan pada kenyataannya kinerja biasa saja.Atribut yang termasuk kedalam kuadaran III adalah merek, banyak dikonsumsi 
orang, prestige/kebanggan, layanan informasi, aroma dan kepadatan.

Kuadran IV

Atribut yang berada di wilayah ini adalah atribut yang nilai rata-rata kepentingannya berada di bawah rata-rata nilai total kepentingan atribut, tetapi secara relatif kinerjanya sudah memuaskan konsumen.Akan tetapi pada penelitian ini berdasarkan hasil analisis data menggunakan metode Importance Performance Analysisketahui bahwa tidak ada atribut produk Cokelat Monggo yang masuk kedalam kuadran IV.

Rekomendasi Strategi Pemasaran Produk Cokelat Monggo

Hasil analisis perilaku konsumen berimplikasi terhadap strategi bauran pemasaran, adapun strategi pemasaran yang dilakukan oleh perusahaan bertujuan untuk memenuhi dan memuaskan kebutuhan serta keinginan pelanggan sasaran (Kotler, 2002). Strategi bauran pemasaran berkaitan dengan empat unsur bauran pemasaran yang terdiri dari product (produk), price (harga), promotion (promosi) dan place (tempat).Adapun rekomendasi yang dapat disusun berdasarkan hasil penelitian ini ke pihak perusahaan adalah sebagai berikut:

Strategi Produk

Atribut kemasan, tekstur, variasi rasa, aftertaste, informasi tanggal kadaluarsa, informasi tanggal kadaluarsa, informasi kandungan gizi dan informasi halal berada pada Kuadran II. Hal ini menjadikan atributatribut tersebut harus dipertahankan dan ditingkatkan kinerjanya oleh pihak Cokelat Monggo. Terutama untuk pencantuman informasi kandungan gizi diusahakan disetiap varian produk Cokelat Monggo.

Atribut merek, aroma dan kepadatan berada di Kuadran III. Secara teori memang peningkatan kinerja dari atribut-atribut tersebut akan memberikan pengaruh yang sangat kecil bagi pelanggan. Namun, untuk atribut merek, aroma dan kepadatan perlu tetap ditingkatkan kinerjanya. Hal ini selaras dengan penelitian terdahulu Sukardi et al (2010) karena termasuk dalam faktor pendorong utama kepuasan konsumen dimensi kualitas produk sehingga perlu ditingkatkan lagi agar sesuai dengan harapan konsumen. Alternatif strategi untuk memperbaiki komposisi bahan atau menambah bahan tertentu untuk memperbaiki kepadatan produk Cokelat Monggo agar tidak cepat meleleh.

\section{Strategi Tempat dan Distribusi}

Atribut kemudahan mendapatkan produk berada pada Kuadran I, hal ini menunjukan bahwa keadaan saluran distribusi belum terlalu baik sampai ke pelosok. Salah satunya di minimarket maupun supermarket masih sulit ditemukan. Alternatif strategi yang dapat dilakukan terkait dengan hal ini adalah dengan memperluas jaringan distribusi produk Cokelat Monggo dan menjalin hubungan baik dengan retail yang menjual produk Cokelat Monggo, misalnya menyediakan prasarana penjualan atau display guna menambah dan meningkatkan pelayanan retail untuk melayani konsumen. Hubungan ini diharapkan dapat terjaga dengan baik sehingga menciptakan kestabilan kontinyuitas produk dan volume penjualan Cokelat Monggo, sehingga Cokelat Monggo dapat menjamin ketersediaan produk. Strategi Harga

Atribut kesesuaian harga dengan kualitas produk berada pada Kuadran II, hal ini menunjukan kinerja atribut kesesuaian harga dengan kualitas produk Cokelat Mongo sudah baik dan harus dipertahankan oleh Cokelat Monggo. Strategi harga dapat ditentukan dengan memperhatikan apabila hendak menaikkan harga, kenaikan harga harus sesuai dengan kualitas produk Cokelat Monggo namun tidak mengurangi cita rasa cokelat itu sendiri. Hal ini didukung dengan alasan pembelian/konsumsi produk Cokelat Monggo oleh konsumen yang paling besar adalah kualitas produk Cokelat Monggo yang bagus. Serta membuat promosi harga produk Cokelat Monggo agar konsumen tertarik membeli. 
Kusumowardhani, dkk. 2019

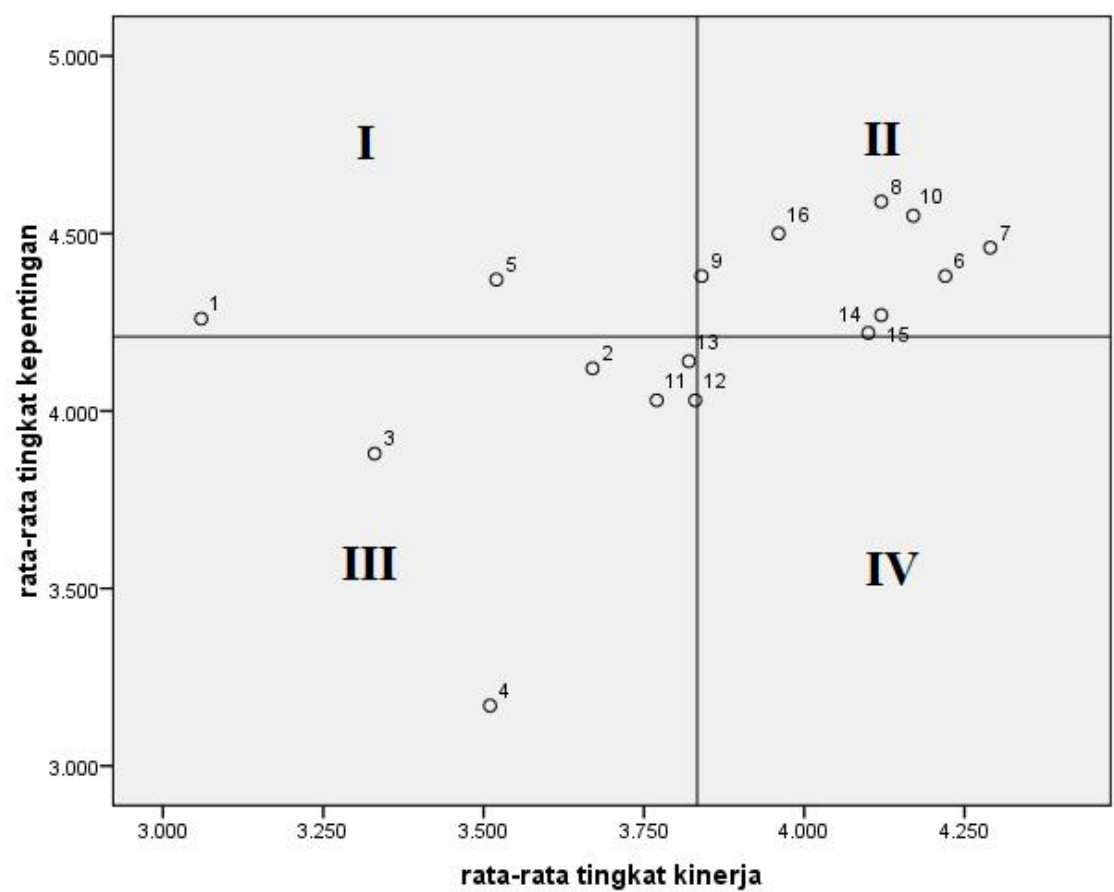

Gambar 2. Diagram Kartesius IPA Atribut Cokelat Monggo

Keterangan :(1) Iklan dan Promosi, (2) Merek, (3) Banyak dikonsumsi Orang, (4) Prestige/kebanggan, (5) Kemudahan Mendapatkan Produk, (6) Kemasan, (7) Variasi Rasa, (8) Informasi Tanggal Kadaluarsa, (9) Informasi Kandungan Gizi, (10) Jaminan Halal, (11) Layanan Informasi, (12) Aroma, (13) Kepadatan, (14) Tekstur, (15) Aftertaste dan (16) Kesesuaian Harga dengan Kualitas.

\section{Strategi Promosi}

Promosi masuk dalam prioritas perusahaan karena dinilai masih kurang untuk kinerjanya karena atribut iklan dan promosi berada di Kuadran III. Alternatif strategi yang dapat dilakukan menjadi sponsor kegiatan tertentu yang dapat meningkatkan citra positif dan untuk menghindari biaya besar dalam promosi, dapat dilakukan dengan metode Word of Mouth (WOM) melalui food influencer sehingga dapat membangun persepsi konsumen mengenai produk Cokelat Monggo. Karena menurut Kasali (2003) bahwa masyarakat kita adalah masyarakat mulut, yaitu masyarakat yang lebih menggunakan mulutnya dalam berkomunikasi.
Atribut layanan informasi sebaiknya perlu ditingkatkan oleh perusahaan. Hal ini selaras dengan penelitian Sukardi (2010) layanan informasi merupakan faktor pendorong dimensi service quality sehingga kinerjanya perlu dipertahankan dan ditingkatkan. Membuat menu khusus untuk kritik dan saran, memperjelas akun resmi Cokelat Monggo disetiap produk maupun iklan dan promosi serta memperbaharui data website, sehingga konsumen dapat dengan mudah melihat website atau mengupdate informasi serta leluasa menyampaikan saran ataupun keluhan. Dengan adanya website, sekaligus dapat dijadikan sebagai sarana promosi. 
Kusumowardhani, dkk. 2019

\section{KESIMPULAN}

Kesimpulan yang dapat diambil adalah sebagai berikut: (1) hasil perhitungan Costumer Satisfaction Index (CSI), tingkat kepuasan konsumen produk Cokelat Monggo yaitu sebesar $76.93 \%$ yang menunjukkan bahwa secara keseluruhan konsumen sudah merasa puas. (2) Alternatif strategi pemasaran yang direkomendasikan yaitu pada strategi produk, pencantuman informasi kandungan gizi disetiap varian produk Cokelat Monggo. Alternatif strategi distribusi yang dapat dilakukan adalah menyediakan prasarana penjualan atau display. Alternatif strategi harga yang disarankan adalah membuat promosi harga produk Cokelat Monggo. Alternatif strategi promosi yang dapat dilakukan menjadi sponsor kegiatan tertentu dan metode Word of Mouth (WOM). Peningkatan layanan informasi dapat dilakukan dengan membuat menu khusus untuk kritik dan saran, memperjelas akun resmi Cokelat Monggo disetiap produk maupun iklan dan promosi serta memperbaharui data website.

\section{Saran}

Saran yang dapat diberikan adalah: (1) survei kepuasan konsumen perlu dilakukan pihak Cokelat Monggo secara berkala agar pihak Cokelat Monggo mengetahui apa yang diinginkan konsumen terhadap produknya. (2) pihak perusahaan sebaiknya segera melakukan upaya-upaya perbaikan terutama pada atribut yang dianggap penting oleh pelanggan tetapi pelaksanaanya belum memuaskan yaitu kebersihan ruangan dan kecepatan pelayanan.

\section{DAFTAR PUSTAKA}

Direktorat Jenderal Perkebunan 2012-2016. Statistik Perkebunan Indonesia Komoditas
Kakao. Kementerian Pertanian Republik Indonesia.

Hasibuan et al. 2012. Policy Analysis of Cocoa Downstream Industry Development (A System Dynamic Approach). Informatika Pertanian. Vol. 21 : $59-67$.

Kasali, R. 2003. Manajemen Public Relation : Konsep dan Aplikasinya di Indonesia. Pustaka Utama Grafiti : Jakarta.

Kementerian Perindustrian. 2016. Industri Kakao Tumbuh Pesat. www.kemenperin.go.id : Jakarta

Kirom, B. 2009. Mengukur Kinerja Pelayanan dan Kepuasan Konsumen. Bandung: Pustaka Reka Cipta.Pronas Produksi PT CIP, Depansar, Bali. Institut Pertanian Bogor. Jurnal Tekonologi Industri Vol 18(2) : 106-117.

Kotler, P. 2002. Manajemen Pemasaran (Terjemahan). Edisi Milenium, jilid 1, Prenhallindo. Jakarta.

Martilla J, James J. 1977. Importance Performnace Analysis. Journal of Marketing. American Marketing Association. Vol 41 : 77-79.

Sukardi et al .2010. Analisis Tingkat Kepuasan Pelanggan Terhadap Produk Corned Pronas Produksi PT CIP, Depansar, Bali. Institut Pertanian Bogor. Jurnal Tekonologi Industri Vol 18(2) : 106-117.

Udayana, I Gusti Bagus . 2011. Peran Agroindustri Dalam Pembangunan Pertanian. Singhadwala, 44. pp. 3-8. ISSN 0852-775 X 